\title{
First report of Alternaria brassicicola causing leaf spots on garlic, an important food and medicinal plant
}

\author{
Iqra Shahzadi ${ }^{1}$, Aqeel Ahmad²*, Nasim Ahmad Yasin ${ }^{3}$, Ghulam Fareed ${ }^{4}$, \\ Yaseen Ashraf ${ }^{3}$, Waheed Akram², Waheed Ullah Khan ${ }^{1}$ and Muhammad \\ Tayyab $^{3}$ \\ ${ }^{1}$ College of Earth and Environmental Sciences, University of the Punjab, Lahore 54590, \\ Pakistan.
}

2Institute of Medicinal Plants, College of Plant Science and Technology, Huazhong Agricultural University, Wuhan 430070, Hubei, P.R. China.

3Institute of Agricultural Sciences, University of the Punjab, Lahore 54590, Pakistan.

${ }^{4}$ Microbilogy \& Environmental Lab, Institute of Soil and Environmental Science, University of Agriculture Faisalabad, Punjab, Pakistan.

\begin{abstract}
Timely reporting new pathogens in an area is very important to design crop cultivation strategies. Current study describes the attack of Alternaria brassicicola over garlic, an important food and medicinal plant in Punjab, Pakistan. Pathogen was successfully isolated over artificial fungal growth medium and its microscopic characteristics were studied morphologically. Its identification was confirmed by targeting ribosomal DNA (ribotyping) prior to its submission in Fungal Culture Bank of Pakistan (FCBP). The isolated pathogen was tested for its pathogenicity under greenhouse conditions. Furthermore, the phylogenetic homology of the pathogen was checked with previously reported fungal isolates. The study was preceded according to the design and requirements of Koch's postulates; and the pathogenicity of the isolated fungal species was confirmed.
\end{abstract}

Key words:

Alternaria brassicicola, homology, phylogenetic, ribotyping, medicinal plant

\section{Received: \\ 02 May 2017 \\ Accepted: \\ 05 June 2017 \\ Published: \\ 07 June 2017}

*Corresponding Author:

Aqeel Ahmad

Institute of Medicinal

Plants, College of Plant

Science and Technology,

Huazhong Agricultural

University, Wuhan 430070

Hubei, P.R. China

Email:

aqeelahmad1

@gmail.com

\section{Citation:}

Iqra, S., Aqeel, A., Nasim, A. Y., Ghulam, F., Yaseen, A., Waheed, A. Waheed, U. K., \& Muhammad, T. (2017). First report of Alternaria brassicicola causing leaf spots on garlic, an important food and medicinal plant. Journal of Medicinal Botany, 1, 08-12. doi: 10.25081/jmb.2017.v1.48

\section{Introduction}

Garlic is an important food and medicinal crop with its equal consumption around the globe (Etkin, 2008). It is incorporated in a number of ways in routine food items of humans (Kim et al., 2013). Besides, the food uses, its medicinal importance can never be overemphasized (Khan et al., 2014). The interest in the potential uses and benefits of garlic has origins in antiquity and is one of the earliest documented usage of plants which has been used in traditional treatment of various disease and maintenance of health (Rivlin, 2001). Therefore, its high yield has always been a point of interest for researchers and farmers.

Diseases affecting garlic crop are paid significant attention in order to attain higher yields of garlic. Even though garlic is an active agent against pathogenic strains (Kumar and Berwal, 1998), early detection and report of new disease is always useful in plant protection

\footnotetext{
CThis article is open access and licensed under the terms of the Creative Commons Attribution License (http://creativecommons.org/licenses/by/4.0/) which permits unrestricted, use, distribution and reproduction in any medium, or format for any purpose, even commercially provided the work is properly cited. Attribution - You must give appropriate credit, provide a link to the license, and indicate if changes were made. 
program (Hussain et al., 2008). Therefore, a new pathogen on garlic crop has been reported in current study. It would be helpful to secure yields, and to plan cultivation strategies for garlic plants.

\section{Methodology \\ Field Sampling}

Dark brown lesions were observed on garlic leaves in Punjab, Pakistan in September 2014. Sample diseased leaves were collected and brought to Fungal Biotechnology Lab, University of the Punjab, Lahore.

\section{Pathogen Isolation}

Infected samples were cut into small pieces 4-6 mm2 and surface sterilized using 10\% bleach (1 $\mathrm{min})$ and $90 \%$ ethanol $(30 \mathrm{sec})$. All samples were sufficiently rinsed in sterilized water prior to air drying, and aseptically inoculated on $2 \%$ Potato Dextrose Agar (PDA) medium and incubated for 5 days at $25^{\circ} \mathrm{C}$ in dark.

\section{Pathogen Identification}

Pathogen was microscopically observed and its micrometric measurements were recorded. Moreover, the morphological features of the pathogen were also observed to identify the culture morphologically. Furthermore, the pathogen was re-identified by First Fungal Culture Bank of Pakistan (FCBP), University of the Punjab and got registered under the Accession\# FCBP-1320. Besides, morphological identification ribotyping of the pathogen was performed by targeting rDNA using a primer set $\mathrm{F}=$ TCC TCC GCT TAT TGA TAT GC and $\mathrm{R}=$ GGA AGT AAA AGT CGT AAC AAG G. Phylogenetic similarity of the pathogen with closely related fungal strains was expressed through a dendrogram.

\section{Pathogenicity Assay}

Isolated pathogen culture was then then tested for its pathogenicity by following Koch's Postulates. Therefore, garlic seedlings of variety Agliobianco were grown from surface sterilized seeds in plastic pots of $5^{\prime \prime}$ diameter under greenhouse conditions $\left(24 \pm 2^{\circ} \mathrm{C}\right)$. Twenty days old seedlings were subjected to pathogen inoculum. The inoculum $\left(1 \times 10^{6}\right.$ conidia/mL) was prepared in sterilized water from 5 days old cultures. Pathogen was sprayed on 15 replicates, whereas 5 replicates of control were treated with sterilized water. All replicates were separately covered with polythene bags to retain moisture and conducive environment for pathogen. Seedlings were incubated for 5 days and examined for development of symptoms, identical to the symptoms observed on field infected samples. The pathogen from infected plants was isolated again from experimentally infected plants to confirm its microscopic characters. Moreover, the pathogen was again tested for its pathogenicity under greenhouse conditions.

\section{Results \\ Field Observations}

Initially, lesions were olivaceous brown, gradually changing into dark grey in color. The lesions had light yellow colored margins, grown and coalesced to develop oblong lesions Fig. 1A.

\section{Microscopic Characters}

A mitosporic fungal colony with dark olivaceous brown appearance and 7.8-8.8 $\mathrm{mm} /$ day growth rate was observed. Spores had no beak and rarely branched chains of up to 23 elements arisen from small pores on conidiophores. Pale to light brown conidia had cylindrical morphology, 1-9 transverse septa and 1-4 longitudinal septa. Conidiophores were ranged from $45-66 \mu \mathrm{m}$ in length. Conidia had dimensions of $27-142 \times 7-22 \mu \mathrm{m}$ with apical cells shorter and brighter than the conidial body. On the basis of morphological characteristics described by Pattanamahakul and Strange et al. (1999) and Reis and Boiteux (2010), pathogen was identified as Alternaria brassicicola (Schwein) Wiltshire (Fig. 1).

\section{Ribotyping}

Fungal species was further identified by amplifying Internal Transcribed Spacer region, rDNA (ITS1-5.8S- ITS2) using primers of ITS4 and ITS5 (White et al., 1990). The resulting sequence of $494 \mathrm{bp}$ was submitted to GenBank (Accession\#KP637149). It had more than 99\% homology with Ab12H (KF542560.1) isolates of A. brassicicola, known as severe pathogens of Brassica in India. Furthermore, the pathogen showed maximum phylogenetic similarity with different strains of $A$. brassicicola reported from different geographical areas around globe (Fig. 2). 

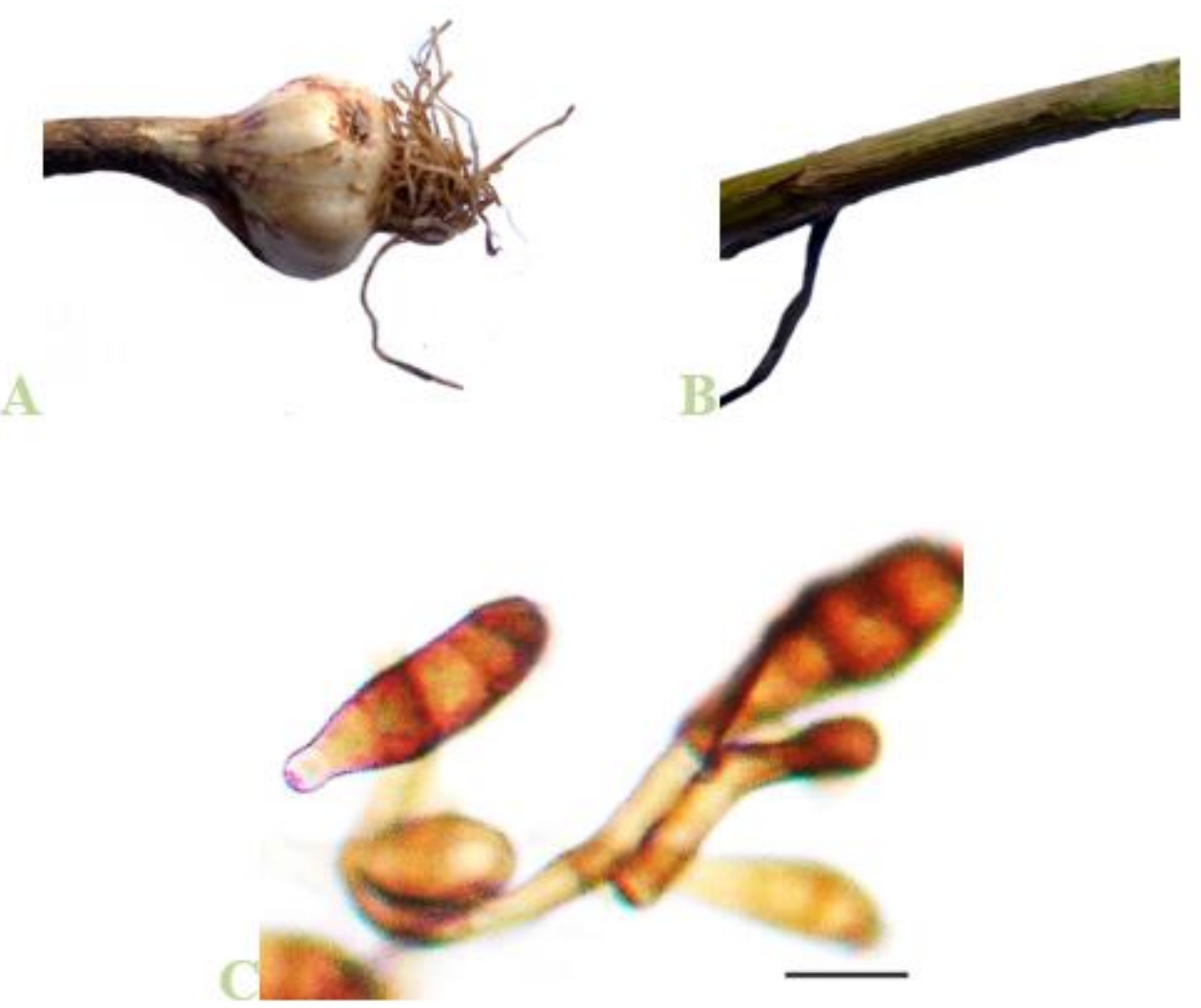

Fig. 1. Characteristic symptoms of the pathogen attack on garlic rhizome (A), leaves (B) and microscopic morphological features of the pathogen (C). Scale bar represents the length of $5 \mu \mathrm{m}$.

\section{Pathogenicity assay}

Seedlings of control treatment didn't exhibit any disease symptoms; however, the symptoms on pathogen treated plants showed identical symptoms as on field infected plants. Moreover, morphological characteristics of reisolated pathogenic strains from greenhouse infected plants were found similar to field isolated pathogen samples.

\section{Discussion}

Alternaria is an economically important genus of plant pathogenic fungi. Most often, it infected plants of family brassicaceae (Nowicki et al., 2012; Mamgain et al., 2013). However, this is the first time, its infection on some nonbrassicaceous plant has been detected. It is the clear indication that the host range of the pathogen is being diversified. It is a signal for experts in plant protection program to pay more attention on this pathogen.

Ribotyping gives a detailed view of inter and intra species genomic polymorphism (Pillet et al., 2012; Akram et al., 2014). It estimates the type of changes needed by a pathogen to change its behaviour e.g. morphology, host range etc. (Ahmad et al.,
2014). Current study reveals that no addition or deletion of a base is required by $A$. brassicicola to shift its pathogenicity over other hosts. Its pathogenicity might be dependent upon extra ribosomal DNA. However, further studies may clear the molecular reasoning of this widening in pathogenicity range.

Up to the best of our knowledge, this is the first report of $A$. brassicicola causing leaf spots on garlic. It will help experts to design future crop cultivation programs. Moreover, it has opened a frontier of research to find out the mechanism of host range expansion by a pathogenic fungal species.

\section{Author contributions}

IS, AA, NAY, WUK and GF performed survey for diseased plants. NAY, WUK, WA and MT, processed samples in the lab. MT, WA, GF and AA recorded and processed data. IS, AA, NAY, wrote the manuscript. All the authors reviewed and finalized the manuscript. 


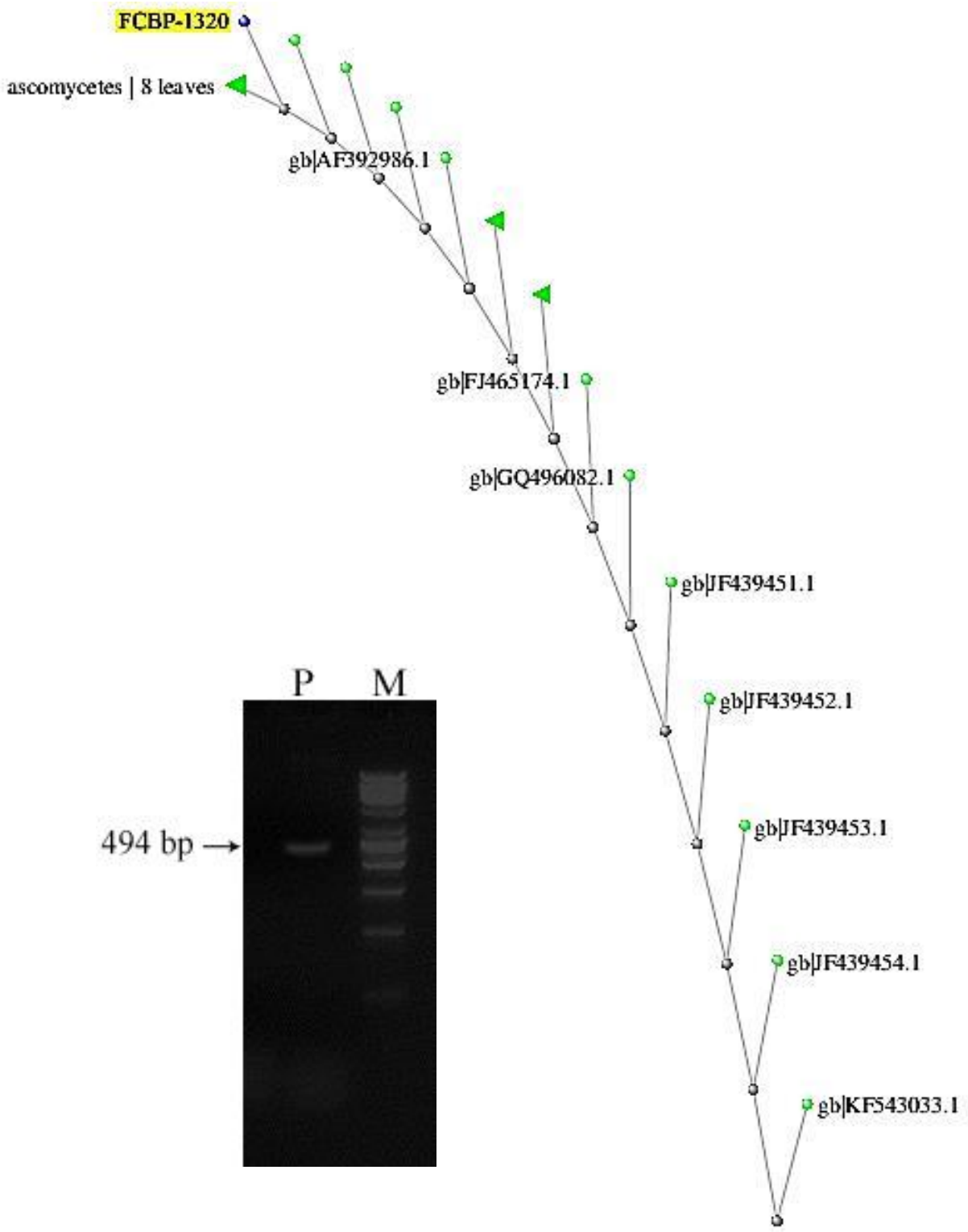

Fig. 2. Dendrogram showing phylogenetic distances among different strains of Alternaria brassicicola. Electrophoresis gel image showing ribosomal DNA of the pathogen $(\mathrm{P})$ and marker $(\mathrm{M})$.

\section{References}

Kim, S. H., Jeong, J. H., \& Nackley, L. L. (2013). Photosynthetic and transpiration responses to light, CO2, temperature, and leaf senescence in garlic: Analysis and modeling. Joumal of the American Society for Horticultural Science, 138(2), 149-156.

Khan, S., Sultan, A., Chand, N., Qureshi, M. S., Tanweer, A. J., Akhtar, A., \& Khan, H. (2014). Garlic (Allium sativum) modulated serum cholesterol level, improved immune status and carcass yield of broilers. Pakistan Journal of Science, 66(2). 66(2): 171-174.

Rivlin, R. S. (2001). Historical perspective on the use of garlic. The Journal of nutrition, 131(3), 951S-954S.

Kumar, M., \& Berwal, J. S. (1998). Sensitivity of food pathogens to garlic (Allium sativum). Journal of Applied Microbiology, 84(2), 213-215. 
Etkin, N. L. (2008). Edible medicines: an ethnopharmacology of food. University of Arizona Press.

Hussain, S., Ali, A., Zahid, M. A., \& Iqbal, S. M. (2008). Multiple disease resistance in lentil germplasm from Pakistan. Pakistan Journal of Botany, 40(2), 897-903.

Pattanamahakul, P., \& Strange, R. N. (1999). Identification and toxicity of Alternaria brassicicola, the causal agent of dark leaf spot disease of Brassica species grown in Thailand. Plant Pathology, 48, 749-755.

Reis, A., \& Boiteux, L. S. (2010). Alternaria species infecting Brassicaceae in the Brazilian neotropics: geographical distribution, host range and specificity. Journal of Plant Pathology, 92(3), 661-668.

Nowicki, M., Nowakowska, M., Niezgoda, A., \& Kozik, E. (2012). Alternaria black spot of crucifers: symptoms, importance of disease, and perspectives of resistance breeding. Vegetable Crops Research Bulletin, 76, 5-19.
Mamgain, A., Roychowdhury, R., \& Tah, J. (2013). Alternaria pathogenicity and its strategic controls. Research Journal of Biology, 1, 1-9.

Pillet, L., Fontaine, D., \& Pawlowski, J. (2012). Intra-genomic ribosomal RNA polymorphism and morphological variation in Elphidium macellum suggests inter-specific hybridization in Foraminifera. PLoS One, 7(2), e32373.

Akram, W., Anjum, T., \& Ahmad, A. (2014). Basal susceptibility of tomato varieties against different isolates of Fusarium oxysporum f. sp. lycopersici. International Journal of Agriculture and Biology, 16, 171-176.

Ahmad, A., Shafique, S., \& Shafique, S. (2014). Molecular basis of antifungal resistance in tomato varieties. Pakistan Journal of Agricultural Sciences, 51(3), 683-687.

White, T. J., Bruns, T., Lee, S., \& Taylor, J. (1990). In: PCR protocols: a guide to methods and applications (Innis M, Gelfand D, Sninsky J, White T, eds.). Pages 315-322. Academic Press, Orlando, Florida. 